\title{
Lying for Bonuses
}

\author{
Junda Chang ${ }^{1}$ \\ ${ }^{1}$ Riverdale Country School, 5250 Fieldston Rd, The Bronx, NY 10471, United States of America \\ Correspondence: Junda Chang, Riverdale Country School, 5250 Fieldston Rd, The Bronx, NY 10471, United \\ States of America.
}

Received: October 3, 2020

Accepted: January 4, 2021

Online Published: January 25, 2021

doi:10.5539/ijps.v13n1p20

URL: https://doi.org/10.5539/ijps.v13n1p20

\begin{abstract}
This study aims to determine whether being in a group setting makes lying easier through the diffusion of responsibility. Participants in three separate conditions, two paired and one isolated control, were asked to roll dice and report results. Participants also had the incentive of earning extra money if the reported number was a four, regardless of the truthfulness of the response. The results showed that participants overwhelmingly reported rolling a four, statistically indicating that many chose to lie. Additionally, one of the two group conditions proved to have significantly higher rates of reported lying than the individual condition (with the other group condition directionally higher but not significantly). The findings suggest that people are more likely to engage in immoral behavior when placed in a group setting as opposed to when acting independently.
\end{abstract}

Keywords: honesty, morality, diffusion of responsibility, morality

\section{Introduction}

In today's ever expanding capitalist societies, there is a constant struggle between money and morality. In California, there is controversy surrounding the "pay-to-stay" program, in which well-off inmates are able to buy their way out of county jail and into an upgraded city jail. Rather than only allowing criminals with light sentences and convictions to participate in this "pay-to-stay" program, the state allows convicted felons with serious charges to take advantage of this system as well, causing victims to feel that justice hasn't been served. However, there are also times when morals are prioritized over money. In a restaurant in Wisconsin, a waitress refused service to openly transphobic customers which resulted in her being fired. After refusing to serve the transphobic customers, the manager called the waitress over, and gave the ultimatum of serving the customers or leaving. The waitress, refusing to ignore moral wrongdoing, chose to forfeit her job and money.

Moral values are sometimes overpowered by desire for money, especially when justifications present themselves. In a market setting, people are regularly reluctant to take morality over money, citing that "if I don't buy or sell, someone else will" (Falk \& Szech, 2013, pg. 710).

Additionally, moral appeal is increasingly ineffective when put against monetary rewards, especially when an inability to obtain money is viewed as a negative consequence (Falk \& Szech, 2013). Ultimately, one considers a multitude of factors when making the choice between money and morality.

\section{Hypothesis}

This study aims to determine whether or not being in a group setting influences one's decisions and actions when choosing between money and morality, specifically the act of lying for monetary gain. I hypothesize that participants placed in a group setting will more likely choose to ignore morals as the diffusion of responsibility allows a lighter moral consequence. The group settings will consist of two conditions, one where both partners have to lie to receive a bonus, and one where only one out of the two have to lie to receive the bonus. In the control condition, individuals will decide whether or not to lie to receive a bonus without a partner.

\section{Literature Review}

Returning to "Morals and Markets," Falk and Szech demonstrated that in a market setting, people are more inclined to disregard morality (Falk \& Szech, 2013). In this study, participants were randomly placed into one of three market settings, individual, bilateral, and multilateral. If the individual or the seller and buyer agreed to kill the mouse, they would receive money. Whereas, if they didn't agree to kill the mouse, no money would be received. In the bilateral and multilateral market settings, either one buyer and one seller, or seven buyers and 
one seller, respectively, negotiated prices. After conducting their research, Falk and Szech concluded that in a market setting, the need for both the buyer and seller to participate contributes to "moral decay" (Falk \& Szech, 2013).

The introduction of another person during the bilateral and multilateral conditions may prompt a feeling of social obligation, increasing the likelihood of choosing to kill the mouse. Similarly, a group setting may also weaken the "moral atmosphere" contributing to higher rates of lying. Additionally, some participants in the group setting may believe that their act of lying is not immoral at all. Due to the conflict of interest presented by the group setting in which one or both participants must lie in order to receive extra money, bounded ethicality causes participants to subconsciously view this decision as an opportunity to demonstrate loyalty to their partner in the experiment (Chugh, Bazerman, \& Banaji, 2005). Essentially, social situations hinder the ability of participants to make quality ethical and moral decisions (Chugh, Bazerman, \& Banaji, 2005).

More specific to the conflict of interest present in this study, "both honesty and benevolence are core components of one's moral character" (Levine \& Schweitzer, 2014, Pg. 1). In situations in which there exists conflict between these core values, participants have shown to value benevolence over honesty (Levine \& Schweitzer, 2014). Furthermore, Levine and Schweitzer have found that contrary to the belief that "dishonesty undermines moral character," individuals actually tend to view those who tell "altruistic lies" to be more moral than "selfish truths" (Levine \& Schweitzer, 2014, Pg. 13). Thus, when lying for the benefit of the group, people may feel that their actions are morally sound.

When placed in a group setting and faced with a pivotal decision that only one member must make, the chances of committing moral wrongdoing are significantly higher (Falk, Neuber, \& Szech, 2020). To compensate for the diffusion of responsibility around pivotal decisions, groups should attribute more "individual responsibility" to each member (Falk, Neuber, \& Szech, 2020). Interestingly in another context, the size of the group also contributes to increased reaction speeds in making pivotal decisions. An experiment surrounding bystander reaction speed during an emergency situation found that as group sizes increased, the reaction times decreased (Darley \& Latané, 1968). The slower reaction speeds and general decrease in willingness to take action in larger groups can also be attributed to the diffusion of responsibility.

This paper's experiment design and procedure was inspired by "Lies in Disguise" (Fischbacher \& Föllmi-heusi, 2013). "Lies in Disguise" used a procedure that required the participant to roll a die, who then reported the number for a monetary reward. The higher the reported number rolled, the more amount of money the participant received. The main advantages of using a similar procedure is that participants are assured that their choice was anonymous, allowing for more comfort with lying and natural behavior. Also the design is simple and easy to use, especially when transferred into an online setting. Furthermore, the procedure allowed for the creation of three different survey conditions.

\section{Method}

This study aimed to recruit 600 participants with 200 in each of the three survey conditions; however, due to an error within Google forms, a marginal amount of extra people answered on each survey condition. Research participants were recruited through Amazon's Mechanical Turk and asked to roll a die and report the result. Research participants were given $\$ 2.00$ if they said that they rolled a four, regardless of honesty. Their responses are anonymous. MTurk participants who answered that they rolled a four were paid $\$ 2.00$ for their participation, other answers were paid one dollar.

Participants were randomly selected to be placed into each survey condition. There are a total of three survey conditions, Individual, Partnered I, and Partnered II. The participants were also informed that even if they admitted to lying, they would still get the monetary bonus. The individual survey condition asked the participant to report what number they rolled, if or if not they lied, and why. The reasoning for why the participant lied was to be selected from a number of multiple choice options and an "other".

The individual survey condition also asked the participant to report what number they rolled and if or if not they lied and why. The reasoning for the why the participant lied was to be selected from a number of multiple choice options and an "other".

The Partnered I survey condition also asked the participant to report what number they rolled and if or if not they lied and why. The reasoning for why the participant lied was to be selected from a number of multiple choice options and an "other". The participants were also informed that they were to be randomly paired with another participant upon completion of the survey and that if one of the two answered that they rolled a four, both shall receive the bonus. 
The partnered II survey condition also asked the participant to report what number they rolled and if or if no they lied and why. The reasoning for why the participant lied was to be selected from a number of multiple choice options and an "other". The Partnered II participants were further informed that they were to be randomly paired with another participant upon completion of the survey and that if and only if both of them reported that they rolled a four, both would receive a bonus.

See Appendix for Surveys.

\section{Results}

Figure 1 demonstrates the responses to each of the three survey conditions. In the Individual Survey Condition, 57.1 percent of the 205 participants answered that they rolled a four. In Partnered Survey Condition I, 66.7 percent of 213 participants answered that they rolled a four. Finally in Partnered Survey Condition II, 62.7 percent of 212 participants answered that they rolled a four. By conducting a $\mathrm{Z}$ test between the Individual Survey Condition and Partnered Survey Condition I, a marginally significant difference is obtained $(p=.054)$. Similarly, a $Z$ test between the Individual Survey Condition and Partnered Survey Condition II revealed a statistically insignificant difference $(p=.30)$. Finally, a $Z$ test between Partnered Survey Condition I and Partnered Survey Condition II also resulted in a statistically insignificant difference $(\mathrm{p}=.40)$. In all, the minute differences between each survey condition showed that with this sample size, any difference between two conditions does not have a clear probable cause.

\section{Frequency of Reported Die Rolls}

87.5

$$
70 .
$$

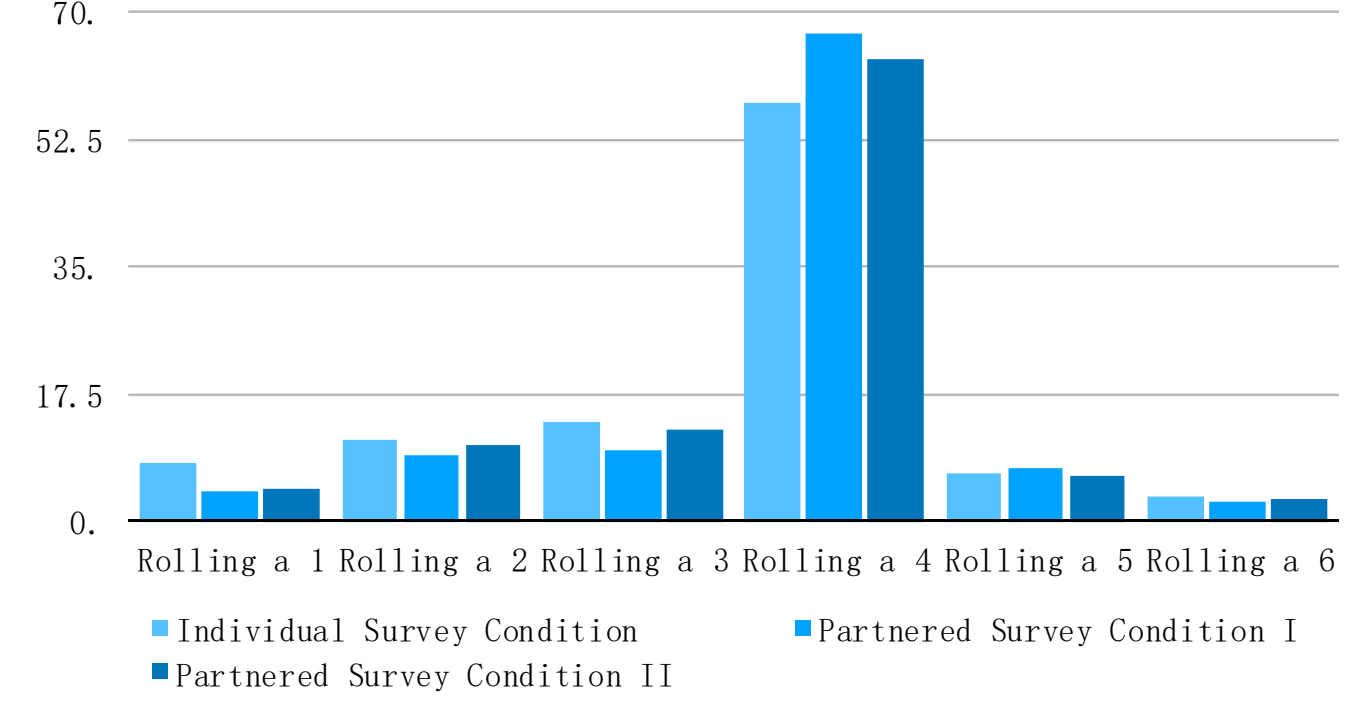

Figure 1 . The responses to the 3 survey conditions in percentages 


\section{Percentages of Respondents Who Admit to}

75. Lying

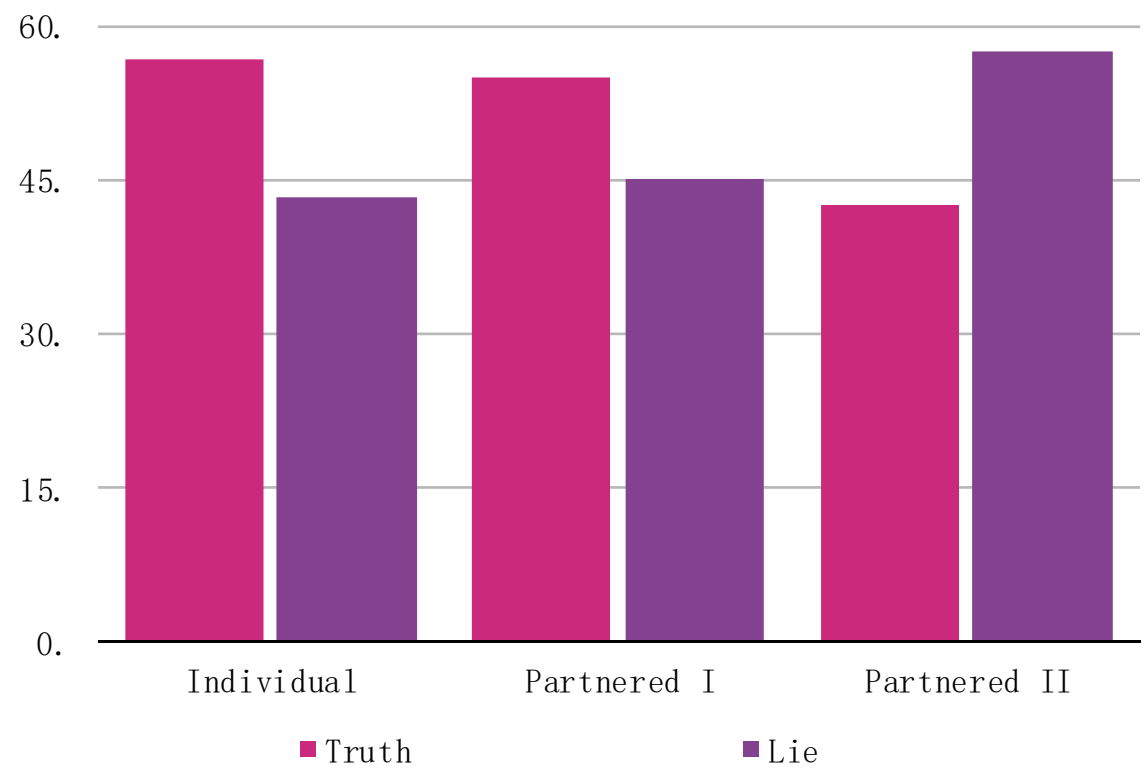

Figure 2. The reported truthfulness of the responses for each survey condition in percentages

Figure 2 demonstrates the truthfulness of the responses to each of the survey conditions.

In the Individual Survey Condition, 43.4 percent of the 205 participants admitted to lying.

In the Partnered I Survey Condition, 45.1 percent of the 213 admitted to lying. Finally, in the Partnered II Survey Condition, 57.5 percent of the 212 admitted to lying. A Z test between Individual Survey Condition and Partnered Survey Condition I showed that the difference was statistically insignificant $(p=.70)$. However, a $Z$ test between the Individual Survey Condition and Partnered Survey Condition II revealed a highly statistically significant difference $(\mathrm{p}=.0043)$. Finally, a Z test between Partnered Survey Condition I and Partnered Survey Condition II resulted in a statistically significant difference $(p=.01)$. The statistically significant differences between Partnered Survey Condition II and both Individual and Partnered Survey Condition I suggests that each member is significantly more inclined to lie when placed in a group where all members are required to have the same reported response.

\section{Discussion}

This study aimed to determine whether or not individuals are more likely to lie in a group setting through the diffusion of responsibility. The statistically significant differences in the truthfulness of the reported responses between Partnered Survey Condition II and both Partnered Survey Condition I and the Individual Survey Condition reveal that the hypothesis was partially correct. The results show that when people are in a group that requires unanimous decisions, the members of the group are more likely to ignore moral consequences to pursue the goal of the group. However, when only one member of the group has to commit a moral misdeed for the group to reach its goal, it is far less likely that any other members of the group will commit the moral misdeed in place of someone. This dynamic reveals that people in a group are willing to lie and engage in immoral behavior when others within the group are doing it as well, resulting in a sense of shared responsibility and guilt.

In this study, sample size was a limitation; thus, the lack of significant differences should not be interpreted to mean no effect. Hypothetically, if the number of participants was raised to 10,000 participants for each survey condition, the difference between the truthfulness of the reported responses between Partnered Survey Condition I and the Individual Survey Condition would become statistically significant, possibly suggesting that no matter what kind of group setting a person is in, they are more inclined to participate in moral misconduct for the benefit of the group. 
Diffusion of responsibility amongst the group members allows for an increased tendency to engage in immoral behavior. This trend is evident to an even higher degree in groups where the ultimate decision must be reached collectively. This may partially be due to social obligation, as once everyone else is doing it, you do not want to be the one that prevents your team from succeeding. Additionally, a higher frequency of lying in a setting similar to Partnered Survey Condition II may be due to an internal struggle between morality and success for the group.

\section{Conclusion}

Ultimately, ethical behavior is about acting in accordance with societal norms and values. There are lots of norms and values that different societies weigh differently. In group settings, there are often conflicts between benevolence and honesty. The diffusion of responsibility lowers the importance of honesty as a group value. Because of the decreasing significance of honesty, an increasing number of people view lying through a more benevolent lens. Due to the now uneven trade-off between benevolence and honesty, more people in group settings may be able to justify their dishonesty as a selfless act for the good of the group, thus increasing the likelihood of lying.

\section{Acknowledgements}

Special thanks to Russell Golman of Carnegie Mellon University.

\section{References}

Aviles, G. (2019, October 17). 'Morals over money': Waitress fired after refusing to serve transphobic customers. NBCNews.com. from https://www.nbcnews.com/feature/nbc-out/morals-over-money-waitress-fired-after-refusing-serve-transpho bic-customers-n1068291

Bazerman, M., Chugh, D., \& Banaji, M. (2005). Bounded Ethicality as a Psychological Barrier to Recognizing Conflicts of Interest. Conflicts of Interest: Challenges and Solutions in Business, Law, Medicine, and Public Policy.

Darley, J., \& Latané, B. (1968). Bystander Intervention in Emergencies: Diffusion of Responsibility. Journal of Personality and Social Psychology, 8(4), 377-383. https://doi.org/10.1037/h0025589

Falk, A., \& Szech, N. (2013). Morals and Markets. Science, 340, 707-711.

Falk, A., Neuber, T., \& Szech, N. (2020). Diffusion of Being Pivotal and Immoral Outcomes. Review of Economic Studies, 87, 2205-2229. https://doi.org/10.1126/science.1231566

Fischbacher, U., \& Föllmi-Heusi, F. (2014). Lies In Disguise. Journal of the European Economic Association, 12(3), 525-547. https://doi.org/10.1111/jeea.12014

Levine, E. E., \& Schweitzer, M. E. (2014). Are Liars Ethical? On the Tension between Benevolence and Honesty. Journal of Experimental Social Psychology, 53, 107-117. https://doi.org/10.1016/j.jesp.2014.03.005

Santo, A., Kim, V., \& Flagg, A. (2017, March 9). Upgrade your jail cell - for a price. Los Angeles Times. Retrieved from https://www.latimes.com/projects/la-me-pay-to-stay-jails/ 


\section{Appendix}

Independent: You are to roll a die or use a random dice roller online once. If you roll a four you will be paid $\$ 2.00$, however there is no way to know if you lied. Thus, even if you didn't roll a four but selected the option that you did, you will still be paid $\$ 2.00$. Whereas, if you select any option that is not rolling a four, you will be paid only $\$ 1.00$.

Research Survey (Individual)

1. What number did you roll

1

2

3

4

5

6

2. Did you lie

Yes

No

3. If the answer to the previous question was "yes", why did you lie?

Lying is a negligible moral offense

Money is more important than morals

I already lie frequently so this is not out of the ordinary

Other:

Partnered I: You are to roll a die or use a random dice roller online once. Upon completion, you will be randomly partnered with another individual who also has taken this survey. If either of you roll a 4 you will be paid 2 dollars, however there is no way to know if you lied. Thus, even if you didn't roll a four but selected the option that you did, you will still be paid two dollars. Whereas if you select any option that is not rolling a four and your partner also happens to select any of the options that are not rolling a four, both of you will be paid only one dollar.

Research Survey (Partnered I)

1. What number did you roll

1

2

3

4

5

6

2. Did you lie

Yes

No

3. If the answer to the previous question was "yes", why did you lie?

Lying is a negligible moral offense

Money is more important than morals

I already lie frequently so this is not out of the ordinary 
The guilt of lying is shared between both partners, making it easier to lie

By lying, I may be committing a very small moral misdeed, however I am also helping my partner, balancing out the morality

Other:

Partnered II: You are to roll a die or use a random dice roller online once. Upon completion, you will be randomly partnered with another individual who also has taken this survey. If and only if both of you answer that you rolled a 4 you will be paid 2 dollars, however there is no way to know if you lied. Thus, even if you didn't roll a four but selected the option that you did, you will still be paid two dollars. Whereas if you select any option that is not rolling a four and your partner also happens to select any of the options that are not rolling a four, both of you will be paid only one dollar.

Research Survey (Partnered II)

1. What number did you roll

1

2

3

4

5

6

2. Did you lie

Yes

No

3. If the answer to the previous question was "yes", why did you lie?

Lying is a negligible moral offense

Money is more important than morals

I already lie frequently so this is not out of the ordinary

The guilt of lying is shared between both partners, making it easier to lie

By lying, I may be committing a very small moral misdeed, however I am also helping my partner, balancing out the morality

Since my partner might lie, by also lying, I am able to ensure that his or her misdeed is not wasted

Other:

\section{Copyrights}

Copyright for this article is retained by the author(s), with first publication rights granted to the journal.

This is an open-access article distributed under the terms and conditions of the Creative Commons Attribution license (http://creativecommons.org/licenses/by/4.0/). 